\title{
BMJ Open Does pre-pregnancy BMI determine blood pressure during pregnancy? A prospective cohort study
}

Ary I Savitri, ${ }^{1}$ Peter Zuithoff, ${ }^{1}$ Joyce L Browne, ${ }^{1}$ Dwirani Amelia, ${ }^{2}$ Mohammad Baharuddin, ${ }^{2}$ Diederick E Grobbee, ${ }^{1}$ Cuno S P M Uiterwaal ${ }^{1}$

To cite: Savitri Al, Zuithoff $P$, Browne JL, et al. Does prepregnancy BMI determine blood pressure during pregnancy? A prospective cohort study. BMJ Open 2016:6:e011626. doi:10.1136/bmjopen-2016011626

- Prepublication history and additional material is available. To view please visit the journal (http://dx.doi.org/ 10.1136/bmjopen-2016011626).

Received 22 February 2016 Revised 10 June 2016 Accepted 21 June 2016

\section{CrossMark}

\footnotetext{
1Julius Center for Health Sciences and Primary Care, Julius Global Health, University Medical Center Utrecht, Utrecht, The Netherlands

${ }^{2}$ Budi Kemuliaan Hospital, Jakarta, Indonesia
}

Correspondence to Ary I Savitri; aryisavitri@gmail.com

\section{ABSTRACT}

Objectives: To evaluate if pre-pregnancy body mass index (BMI) determines blood pressure throughout pregnancy and to explore the role of gestational weight gain in this association. In addition, the effects of prepregnancy BMI and gestational weight gain on the occurrence of gestational hypertension and preeclampsia were investigated.

Design: Prospective cohort study.

Setting: Maternal and child health primary care referral centre, Jakarta, Indonesia.

Population and measurements: 2252 pregnant women visiting Budi Kemuliaan Hospital and its branch for regular antenatal care visits from July 2012 to April 2015. Pre-pregnancy BMI $\left(\mathrm{kg} / \mathrm{m}^{2}\right)$ was based on selfreported pre-pregnancy weight and measured height at first visit. Gestational weight gain was calculated as weight at the day of delivery minus the pre-pregnancy weight. Systolic blood pressure (SBP) and diastolic blood pressure (DBP) were measured during pregnancy at every visit. Linear mixed models were used to analyse this relation with repeated blood pressure measures as the outcome and pre-pregnancy $\mathrm{BMI}$ as the predictor. When looking at gestational hypertension and pre-eclampsia as outcomes, (multiple) logistic regression was used in the analysis. Results: Independent of pre-pregnancy BMI, SBP and DBP increased by $0.99 \mathrm{~mm} \mathrm{Hg} /$ month and $0.46 \mathrm{~mm} \mathrm{Hg} / \mathrm{month}$, respectively. Higher pre-pregnancy $\mathrm{BMI}$ was associated with higher pregnancy SBP $\left(0.25 \mathrm{~mm} \mathrm{Hg} / \mathrm{kg} / \mathrm{m}^{2} ; 95 \% \mathrm{Cl} 0.17\right.$ to $\left.0.34 ; \mathrm{p}<0.01\right)$ and DBP $\left(0.18 \mathrm{~mm} \mathrm{Hg} / \mathrm{kg} / \mathrm{m}^{2} ; 0.13\right.$ to $\left.0.24 ; p<0.01\right)$ in adjusted analysis. Every $1 \mathrm{~kg} / \mathrm{m}^{2}$ higher pre-pregnancy BMI was associated with $6 \%$ and $9 \%$ higher odds for gestational hypertension (adjusted OR (aOR) 1.06; $95 \% \mathrm{Cl} 1.03$ to $1.09 ; \mathrm{p}<0.01)$ and pre-eclampsia $(\mathrm{aOR}$ $1.09 ; 1.04$ to $1.14 ; p<0.01)$. Accounting for gestational weight gain did not attenuate these associations.

Conclusions: Pre-pregnancy BMI determines the level, but not the change, of blood pressure in pregnancy and is linked to higher odds for gestational hypertension and pre-eclampsia, independent of gestational weight gain.

\section{INTRODUCTION}

Over the past decades, the prevalence of overweight and obesity among women of reproductive age has increased tremendously

\section{Strengths and limitations of this study}

This study was conducted in the population with a low prevalence of maternal smoking and alcohol/drug abuse; therefore, the effect of prepregnancy body mass index on blood pressures could be analysed in isolation from such factors.

- Analysis was based on the assumption of linearity between blood pressures increase in pregnancy and gestational age at measurement; thus, it may not reflect actual blood pressure trajectory in pregnancy.

- Pre-pregnancy weight was retrospectively asked during interview at the first antenatal care visit; therefore, some inaccuracies may exist.

in developed and developing countries. ${ }^{1}$ High body mass index (BMI), together with high systolic blood pressure (SBP), are known as the leading risk factors for mortality and disability-adjusted life-years in women worldwide, ${ }^{2}$ mainly through manifestation of cardiovascular diseases and metabolic disorders. ${ }^{3}$

Being overweight or obese also puts women at risk for developing various pregnancy complications, including gestational hypertension and pre-eclampsia, ${ }^{4-10}$ and higher risk for cardiovascular events later in life. $^{11}$ As compared with normal weight women, overweight and obese women have 3-5 times increased risk for pre-eclampsia. ${ }^{3}$ Higher baseline BMI recorded at the first antenatal visit has also consistently been linked to higher risk of hypertensive disorders of pregnancy (HDP). ${ }^{12}{ }^{13}$ Several studies reported that pre-pregnancy BMI influences SBP and diastolic blood pressure (DBP) levels during pregnancy. ${ }^{5}$ 14-16 However, studies that reported the effect of pre-pregnancy BMI on the rate of change in SBP and DBP are limited. Furthermore, the role of weight gain on the relation between pre-pregnancy BMI and blood pressure during pregnancy is also less consistent. Several studies reported that excessive 
gestational weight gain was associated with higher risk of gestational hypertension and pre-eclampsia, ${ }^{5} 1617$ but some other studies did not find such associations. ${ }^{18} 19$ It is also unclear whether the relation between obesity and HDP was mediated by excessive weight gain, as overweight or obese women were shown to be more likely to experience excessive weight gain as compared with women with normal BMI. ${ }^{20}$

In the present study, we investigated the effect of prepregnancy BMI, as a proxy for maternal adiposity, on several blood pressure measures throughout pregnancy and on the occurrence of gestational hypertension and pre-eclampsia. Furthermore, we explored the influence of gestational weight gain in these associations.

\section{METHODS}

\section{Study population}

This study was based on a prospective cohort of 2252 pregnant women in the private mother-child health Budi Kemuliaan Hospital and its branch (Budi Kemuliaan Petojo) in Jakarta, Indonesia. Women were recruited at first visits for antenatal care (ANC) between July 2012 and October 2014 and followed up until delivery, the last in April 2015. All women who attended ANC visits were invited and asked to sign written informed consent.

Midwives obtained interview information regarding women's demography including age and socioeconomic background (monthly family income, education, employment status). Women's education was categorised as low if the women had finished elementary or junior high school, medium if they finished senior high school or high if they attained education from university. Women's employment status was classified as not working, working in a formal job, or working in a nonformal job (trader, nanny, cleaning service, etc). Women's clinical data included medical history, information on current pregnancy (last menstrual period (LMP), pre-pregnancy weight and weight at every ANC visit), women's obstetrical history (parity, previous pregnancy complications, previous mode(s) of delivery) and family history of diseases (including family history of hypertension and diabetes mellitus type 2 ).

\section{Anthropometric measures}

Pre-pregnancy weight was self-reported at the first ANC and height was measured using standardised statometers. Pre-pregnancy BMI was then calculated as prepregnancy weight in kilograms divided by the square of height in metres. Women's weight was measured at each ANC visit using standard scales.

\section{Outcome measurements}

Women's SBP and DBP were routinely measured by midwives at every ANC visit. SBP and DBP were measured once per visit in seated position, after a minimum 30 min rest, using a mercury sphygmomanometer.
Gestational hypertension and pre-eclampsia were classified according to the definitions from the International Society for the study of Hypertension in Pregnancy (ISSHP) ${ }^{21}$ Gestational hypertension was defined as SBP of $140 \mathrm{~mm} \mathrm{Hg}$ or more and/or DBP of $90 \mathrm{~mm} \mathrm{Hg}$ or more on two occasions in a woman with no hypertension prior to 20 weeks of gestation. Pre-eclampsia was defined as gestational hypertension with proteinuria.

\section{Confounding variables and intermediate variables}

Women's age, parity, secondhand smoking exposure and monthly family income (proxy for socioeconomic status) were a priori considered as possible confounders. Age was calculated as the difference between the dates of birth and of women's first ANC visit. Parity was classified as nulliparous or multiparous. Data on secondhand smoking exposure were used instead of active smoking because few $(<1 \%)$ of these pregnant women smoke. Monthly family income was asked to the women as an estimate range. Gestational age at delivery was derived from the date of LMP and the date of delivery.

As a possible intermediate factor, gestational weight gain was calculated as weight on the day of delivery minus pre-pregnancy weight in kilograms.

\section{Data analysis}

Baseline characteristics were described by pre-pregnancy BMI tertiles and group differences were tested using $\chi^{2}$, one-way analysis of variance or Kruskal-Wallis tests where appropriate. Skewed data were reported as median and IQR. Associations between pre-pregnancy BMI and blood pressures were analysed using (un)adjusted linear mixed models for repeated measures, with corresponding $95 \% \mathrm{CI}$ and $\mathrm{p}$ values. Furthermore, to investigate whether gestational weight gain acted as an intermediate factor in this association, we developed an explanatory model which included variables on gestational weight gain. Analyses about the effects of pre-pregnancy BMI on women's risk of developing gestational hypertension and pre-eclampsia were performed using (multiple) logistic regression.

The pattern of blood pressure changes during pregnancy was plotted for each pre-pregnancy BMI tertile by fitting (adjusted) linear mixed models separately with SBP and DBP as the outcomes. The estimated marginal means of SBP and DBP at 13, 16, 19, 22, 25, 28, 31, 34, 37 and 39 weeks of gestation were used to describe the blood pressure trajectory during pregnancy. The baseline gestational age was set at 13 weeks because this was the median gestational age of the first measurement at the ANC visit. Thirty-nine weeks was set as the last BP measurement since this was the median gestational age at delivery. The relation between blood pressure and gestational age (time) was assumed to be linear over the course of pregnancy, as our main goal in this analysis was the mutual ranking of women's blood pressure. In addition, the pattern of weight increase during pregnancy was also presented separately for women in each 
pre-pregnancy BMI tertile using the same approach. Analyses were performed based on non-missing data. All statistical analyses were performed using IBM SPSS (V.21 for Windows).

\section{RESULTS}

Figure 1 provides the study flow chart. Owing to missing data on pre-pregnancy BMI, the analysis concerned 2031 women. Baseline characteristics of women according to tertiles of pre-pregnancy BMI are presented in table 1. As compared with the highest BMI tertile, women in the first and second tertiles were younger, more likely nulliparous and had higher total gestational weight gain. Fewer women in the lowest tertile had attained high education. More women in the highest tertile did not work or worked in a non-formal sector. Monthly family income slightly differed with prepregnancy BMI. No difference was found with respect to women's smoking status, secondhand smoking exposure and gestational age at the first visit and at delivery.

Table 2 shows that higher pre-pregnancy BMI was associated with a significantly higher SBP and DBP, both crude and confounding adjusted. The explanatory model shows that further accounting for total gestational weight gain did not attenuate the associations. Adjustments for other measures of weight gain were also performed, by adding a variable of weight gain measured at each ANC visit or a variable of weight gain for

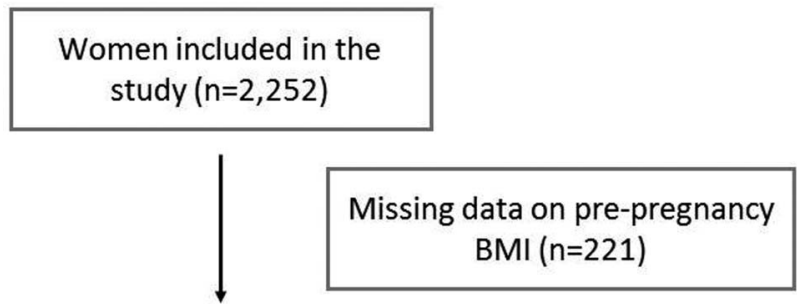

Women in the analyses $(n=2,031)$

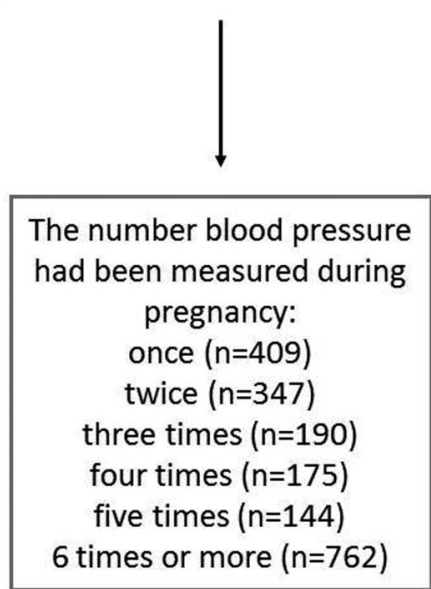

Figure 1 Flow chart of study participants. BMI, body mass index. gestational age and women's pre-pregnancy weight into the adjusted model. However, the use of these measures did not change the findings compared with the presented measurement for gestational weight gain (data not shown).

In online supplementary material 1 , we present the effect estimates if twin pregnancies were excluded from the analysis $(n=26)$. There were no significant differences found as compared with the analysis with twin pregnancies included.

There were 264 women $(13.0 \%)$ in our study who were diagnosed with gestational hypertension and 81 women $(4.0 \%)$ with pre-eclampsia. In table 3 , the associations between pre-pregnancy BMI and occurrence of gestational hypertension and pre-eclampsia were presented. Higher pre-pregnancy BMI was associated with higher odds for gestational hypertension and preeclampsia, in the crude and adjusted models. Adjustment for total gestational weight gain in the explanatory model did not attenuate the associations.

Throughout pregnancy, SBP was estimated to increase by $0.99 \mathrm{~mm} \mathrm{Hg} /$ month while DBP increased by $0.46 \mathrm{~mm} \mathrm{Hg} /$ month in all women, independent of their pre-pregnancy BMI tertiles and other possible confounders. Figure 2 shows that mean blood pressures were consistently higher with higher pre-pregnancy BMI, although the pace of increase did not seem to be affected. The lines that depict the pattern of change in SBP and DBP during pregnancy appeared to be parallel in women from different pre-pregnancy BMI tertiles. In addition, no interaction was found between prepregnancy BMI and gestational age $(p=0.91$ in the confounder-adjusted model).

Figure 3 shows the pattern of weight gain in pregnancy by pre-pregnancy BMI tertile. The level of gestational weight gain differed according to women's pre-pregnancy BMI tertiles. The mean gestational weight gain of women in the first, second and third tertile prepregnancy BMI was 14.3, 12.8 and $10.2 \mathrm{~kg}$ consecutively.

\section{DISCUSSION}

This study shows that pre-pregnancy BMI determines the level of SBP and DBP in pregnancy, but not the pace of blood pressure increase. Pre-pregnancy BMI was also positively associated with the risk of gestational hypertension and pre-eclampsia. The effect was independent of gestational weight gain.

The strength of this study is its prospective design. Furthermore, our study differed from other studies largely conducted in the Western countries where poor health behaviours, such as smoking, alcohol consumption and drug abuse, were more common among obese/ overweight women. ${ }^{22}{ }^{23}$ The proportion of women who have these habits is very low in Indonesia, ${ }^{24}{ }^{25}$ as shown by the data from the women involved in this study. This enabled us to evaluate the effect of pre-pregnancy BMI, as a measure of adiposity, in isolation from such factors. 
Table 1 Baseline characteristics of women by tertiles of pre-pregnancy BMI

\begin{tabular}{|c|c|c|c|c|}
\hline \multirow[b]{2}{*}{ Characteristics } & \multicolumn{3}{|c|}{ Tertiles of pre-pregnancy BMI } & \multirow[b]{2}{*}{ p Value } \\
\hline & Low & Middle & High & \\
\hline Number (\%) & 675 (33.2) & $684(33.7)$ & $672(33.1)$ & \\
\hline BMI $\left(\mathrm{kg} / \mathrm{m}^{2}\right)$, median (minimum, maximum) & $18.6(12.5,20.3)$ & $22.1(20.3,23.9)$ & $26.7(23.9,47.3)$ & $<0.01^{*}$ \\
\hline Age (years), mean (SD) & $26.6(5.6)$ & $28.6(5.6)$ & $30.5(5.7)$ & $<0.01 \dagger$ \\
\hline Women's education & & & & $0.03 \ddagger$ \\
\hline Low education (\%) & $170(25.2)$ & $144(21.1)$ & $132(19.7)$ & \\
\hline Middle education (\%) & 413 (61.3) & $415(60.8)$ & 415 (61.9) & \\
\hline High education (\%) & $91(13.5)$ & $124(18.2)$ & $123(18.4)$ & \\
\hline Women's employment status & & & & $0.01 \ddagger$ \\
\hline Not working (\%) & $385(57.2)$ & $398(58.6)$ & $428(63.9)$ & \\
\hline Non-formal job (\%) & $44(6.5)$ & $52(7.7)$ & $57(8.5)$ & \\
\hline Formal job (\%) & $244(36.3)$ & $229(33.7)$ & $185(27.6)$ & \\
\hline Monthly family income & & & & $0.01 \ddagger$ \\
\hline <IDR1 million (\%) & $68(10.1)$ & $63(9.2)$ & $68(10.1)$ & \\
\hline IDR1-2.5 million (\%) & $320(47.4)$ & $308(45.0)$ & 291 (43.3) & \\
\hline IDR2.5-5 million (\%) & 204 (30.2) & $216(31.6)$ & 203 (30.2) & \\
\hline More than IDR5 million (\%) & $29(4.3)$ & $59(8.6)$ & $45(6.7)$ & \\
\hline Refused to answer (\%) & $54(8.0)$ & $38(5.6)$ & $65(9.7)$ & \\
\hline Nulliparity (\%) & $251(55.8)$ & $182(36.6)$ & $132(25.7)$ & $<0.01 \ddagger$ \\
\hline Women's smoking status & & & & $0.46 \ddagger$ \\
\hline Yes, sometimes (\%) & $3(1.1)$ & $2(0.7)$ & $3(1.0)$ & \\
\hline Yes, everyday (\%) & $4(1.5)$ & $1(0.3)$ & $1(0.3)$ & \\
\hline Partner's smoking status & & & & $0.62 \ddagger$ \\
\hline Yes, sometimes (\%) & $42(15.3)$ & $40(14.0)$ & $35(11.8)$ & \\
\hline Yes, everyday (\%) & $125(45.6)$ & $136(47.7)$ & $153(51.5)$ & \\
\hline Total gestational weight gain $(\mathrm{kg})$, mean (SD) & $14.3(7.0)$ & $12.8(6.5)$ & $10.2(7.1)$ & $<0.01 \dagger$ \\
\hline Gestational age at first visit (weeks), median (IQR) & $13.7(17.0)$ & $12.1(17.3)$ & $12.7(16.8)$ & $0.27^{\star}$ \\
\hline Gestational age at delivery (weeks), median (IQR) & $39.1(2.3)$ & $39.3(2.1)$ & $39.3(2.3)$ & $0.10^{*}$ \\
\hline Preterm birth (<37 weeks gestation) (\%) & $50(7.4)$ & $39(5.7)$ & $34(5.1)$ & $0.18 \ddagger$ \\
\hline Post-term birth (>42 weeks gestation) (\%) & $23(3.4)$ & $30(4.4)$ & $32(4.8)$ & $0.44 \ddagger$ \\
\hline
\end{tabular}

Pre-pregnancy BMI was calculated from the prepregnancy weight that was based on interview. We are aware that it could have limited accuracy. The main analysis was based on the assumption of linearity of the association between increase in blood pressures during pregnancy with gestational age. Therefore, although the graph could accurately describe the relative effect and the rankings of pre-pregnancy BMI tertiles on SBP and DBP, it may not fully reflect the actual absolute trajectory of blood pressure changes during pregnancy. Previous studies reported that blood pressure decreases from early pregnancy to mid-pregnancy and then increases until late pregnancy. ${ }^{14} 1926$ However, our BP measurement began at around 13 weeks of gestation, when SBP and DBP are about to approach their lowest level. Owing to missing data, analyses were limited to women with complete data on the determinant, pre-pregnancy BMI, and outcomes, SBP and DBP, but both were fairly complete. About $20 \%$ of the women in this study had only one BP measurement. Half of these women were referred to our hospital at a later stage of pregnancy and therefore assessments from the referring healthcare facilities were taken into account in diagnosing gestational hypertension and preeclampsia. The other women only came once to our hospital for consultation and continued their ANC visits at other healthcare facilities; consequently, gestational hypertension and pre-eclampsia could not be ruled out. This may, to some extent, have led to the underestimated prevalence of both gestational hypertension and preeclampsia reported in this study. Sensitivity analyses, by including women with at least two, three and four BP measurements, have been done (shown in online supplementary materials 2-7) and gave results that are comparable to the overall analyses (tables 2 and 3). The same results also appeared when we restricted the analysis to women with two or more BP measurements who were not diagnosed with gestational hypertension or preeclampsia (see online supplementary material 8). This suggests that the effect estimates presented in this study are relatively unbiased. Finally, owing to very few women who had first trimester ultrasound crown-rump length measurement, gestational age was based on the LMP.

Classification of pre-pregnancy BMI was based on the tertile, rather than using the WHO cut-off criteria. 
Table 2 Effect of pre-pregnancy BMI on systolic and diastolic blood pressure during pregnancy

\begin{tabular}{|c|c|c|c|}
\hline & \multicolumn{2}{|c|}{ Coefficient $95 \% \mathrm{Cl}$} & p Value \\
\hline \multicolumn{4}{|c|}{ Systolic blood pressure } \\
\hline Crude model & 0.32 & 0.24 to 0.40 & $<0.01$ \\
\hline Adjusted model ${ }^{*}$ & 0.25 & 0.17 to 0.34 & $<0.01$ \\
\hline $\begin{array}{l}\text { Explanatory } \\
\text { model } †\end{array}$ & 0.41 & 0.15 to 0.66 & $<0.01$ \\
\hline \multicolumn{4}{|c|}{ Diastolic blood pressure } \\
\hline Crude model & 0.22 & 0.16 to 0.27 & $<0.01$ \\
\hline Adjusted model ${ }^{*}$ & 0.18 & 0.13 to 0.24 & $<0.01$ \\
\hline $\begin{array}{l}\text { Explanatory } \\
\text { model† }\end{array}$ & 0.27 & 0.08 to 0.45 & $<0.01$ \\
\hline \multicolumn{4}{|c|}{$\begin{array}{l}\text { Results are expressed as mixed model coefficients of systolic an } \\
\text { diastolic blood pressure in } \mathrm{mm} \mathrm{Hg} \text { for every } 1 \mathrm{~kg} / \mathrm{m}^{2} \text { increase in } \\
\text { pre-pregnancy BMl. } \\
{ }^{\star} \text { Adjusted for maternal age, parity, second-hand smoking } \\
\text { exposure and socioeconomic status (monthly family income). } \\
\text { †As * and for total gestational weight gain (difference between } \\
\text { maternal weight measured at the day of delivery from the } \\
\text { pre-pregnancy weight). } \\
\text { BMI, body mass index. }\end{array}$} \\
\hline
\end{tabular}

Using this data-driven approach, a relatively comparable number of women were classified in each group, ensuring sufficient power for statistical testing. Furthermore, there has been uncertainty about an appropriate BMI cut-off for the Asian population. Several studies recommend a lower cut-off for overweight and obesity in the Asian population, but some others do not. ${ }^{27}$

Our study showed that pre-pregnancy BMI influences the level of SBP and DBP during pregnancy. This effect was present consistently over the course of pregnancy. It was in accordance with the reports from previous studies. ${ }^{5} 141528$ Almost similar to our findings, a study which explored the relation between blood pressure during pregnancy with gestational age and prepregnancy BMI as continuous scale measurements also

Table 3 Effect of pre-pregnancy BMI on the risk for developing gestational hypertension and pre-eclampsia

\begin{tabular}{|c|c|c|c|}
\hline & OR & $95 \% \mathrm{Cl}$ & p Value \\
\hline \multicolumn{4}{|c|}{ Gestational hypertension } \\
\hline Crude model & 1.07 & 1.04 to 1.10 & $<0.01$ \\
\hline Adjusted model ${ }^{*}$ & 1.06 & 1.03 to 1.09 & $<0.01$ \\
\hline $\begin{array}{l}\text { Explanatory model† } \\
\text { Pre-eclampsia }\end{array}$ & 1.10 & 1.05 to 1.14 & $<0.01$ \\
\hline Crude model & 1.09 & 1.05 to 1.14 & $<0.01$ \\
\hline Adjusted model ${ }^{*}$ & 1.09 & 1.04 to 1.14 & $<0.01$ \\
\hline Explanatory model† & 1.19 & 1.11 to 1.27 & $<0.01$ \\
\hline \multicolumn{4}{|c|}{$\begin{array}{l}\text { Results are expressed as OR ( } 95 \% \mathrm{Cl} \text { ) for every } 1 \mathrm{~kg} / \mathrm{m}^{2} \text { increase } \\
\text { in pre-pregnancy BMI from (multiple) logistic regression. } \\
{ }^{*} \text { Adjusted for maternal age, parity, secondhand smoking exposure } \\
\text { and socioeconomic status (monthly family income). } \\
\text { †As * and for total gestational weight gain (difference between } \\
\text { maternal weight measured at the day of delivery from the } \\
\text { pre-pregnancy weight). } \\
\text { BMI, body mass index. }\end{array}$} \\
\hline
\end{tabular}

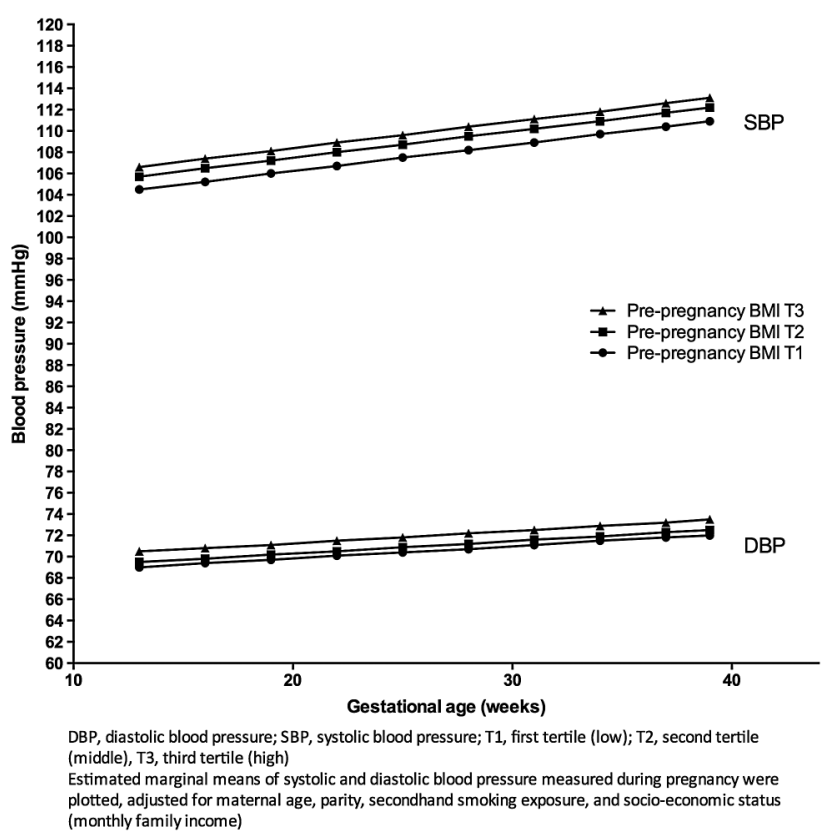

Figure 2 Effect of pre-pregnancy BMI tertiles on systolic and diastolic blood pressure during pregnancy. BMI, body mass index.

found that SBP and DBP levels generally increased with higher pre-pregnancy BMI at any gestational age. ${ }^{16}$

In this study, SBP and DBP were increased by 0.25 and $0.18 \mathrm{~mm} \mathrm{Hg}$ per BMI unit, respectively. These findings were similar to those in a previous study ${ }^{28}$ which reported an increased mean arterial pressure (MAP) of $0.21 \mathrm{~mm} \mathrm{Hg}$ per BMI unit, but were smaller compared with another study ${ }^{5}$ which reported the mean differences of blood pressure in the first, second and third trimesters of 1.03, 0.98 and $0.89 \mathrm{~mm} \mathrm{Hg}$ for SBP per BMI unit and $0.83,0.81$ and $0.74 \mathrm{~mm} \mathrm{Hg}$ for DBP per BMI

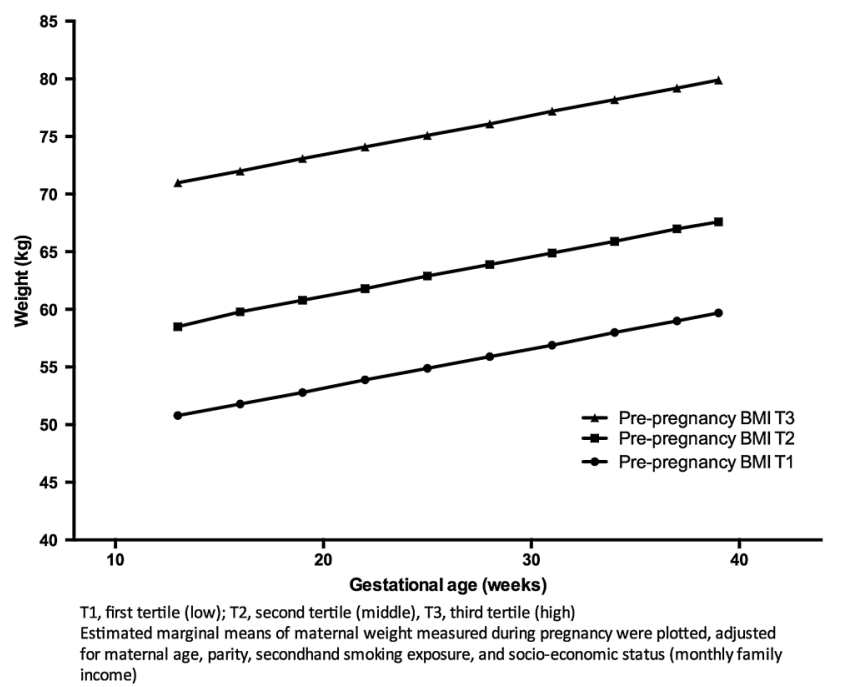

Figure 3 Increase in maternal weight during pregnancy according to pre-pregnancy BMI tertiles. BMI, body mass index. 
unit. These discrepancies could be attributed to differences in variables included in the adjustment model, where in the latter study gestational weight gain was taken into account in the adjusted model but not in our analysis. Furthermore, women's BMI in that study may be higher since there were more overweight and obese women $(27.6 \%)$ than in our study $(24.8 \%)$. Finally, differences in women's ethnicity could also contribute to these differences. To the best of our knowledge, we are among the first to study this in Asian women.

HDP are a spectrum of diseases that encompass chronic hypertension, gestational hypertension, (superimposed) pre-eclampsia and HELLP (haemolysis, elevated liver enzymes and low platelets) syndrome. ${ }^{21} 29$ Our findings were also in accordance with several studies which demonstrated the relation between higher prepregnancy BMI and increased risk of gestational hypertension and pre-eclampsia. ${ }^{10} 17$ 30-34 These were also in line with studies that took obesity or BMI recorded at the first ANC as the determinant. ${ }^{34} 68121335-42$

In this study, we found that pre-pregnancy BMI did not materially affect the pace of increase in blood pressure during pregnancy. An interaction term between BMI tertiles and gestational age that was introduced into the model showed non-significant $p$ values, suggesting that the relation between BMI and blood pressures did not depend on gestational age. The increases in SBP and DBP were running in parallel independent of women's pre-pregnancy BMI. A previous study ${ }^{15}$ also supports our finding as it showed relatively unchanged mean differences of SBP and DBP between various prepregnancy BMI groups in all trimesters. In contrast, another study showed that the pace of increase in BP did vary across BMI group and gestational age, with a ceiling effect which attenuated the increase in BP in higher BMI groups, particularly in later stages of pregnancy. ${ }^{16}$

As compared with women with normal range prepregnancy BMI, women who were overweight or obese before pregnancy had higher risk for excessive weight gain during pregnancy. ${ }^{20}$ Further, this excessive weight gain could synergistically amplify the risk of preeclampsia in obese women. ${ }^{32}$ Our finding in unselected pregnant women shows that gestational weight gain did not mediate the effect of pre-pregnancy BMI on blood pressure level during pregnancy, as shown by the unattenuated effect estimates. Our overall finding is in accordance with a study in Sweden showing correlation between DBP during pregnancy with women's baseline BMI, but not with their gestational weight gain. ${ }^{19}$ Another study also showed that excessive weight gain did not increase the risk of pre-eclampsia, ${ }^{18}$ although it raised the risk of transient hypertension. Many other studies, however, reported a positive relation between excessive weight gain and higher risk of HDP that was independent of pre-pregnancy BMI. $^{5} \quad 17 \quad 30-34 \quad 43$ Nevertheless, it is important to note that these studies used excessive gestational weight gain as a determinant, while in our study gestational weight gain was evaluated as an explanatory variable in a continuous scale measurement.

The pathophysiological mechanism to explain the association between pre-pregnancy BMI and blood pressure levels during pregnancy remains unclear. It has been speculated that adiposity causes a state of increased inflammation, hyperleptinaemia, hyperinsulinaemia and insulin resistance which further leads to disturbances in autonomic function such as sympathetic nervous activation. These mechanisms appeared to be similar in pregnancy and outside of pregnancy, as has been extensively studied among pre-eclamptic pregnant women ${ }^{44-46}$ as well as in obese and hypertensive women. ${ }^{16}{ }^{47-49}$ Obesity may also contribute to the dysregulation of leptin function, which consequently causes hypertension, and alternatively hyperleptinaemia itself could have a direct effect on the increased level of inflammation and raise in blood pressure. ${ }^{45}$ In contrast, several studies in non-pregnant populations suggested that the development of hypertension may precede the weight gain through pregnancy. ${ }^{50} 51$ Sympathetic hyperactivity in patients with hypertension might downregulate $\beta$-adrenergic receptors, which caused a decrease in thermogenic response and therefore increased their propensity to gain weight.

Notably, an adaptive mechanism, which involves maternal systemic inflammatory response through insulin resistance, occurs in all pregnancies, with pre-eclamptic pregnancies being in the extreme end of the continuum. ${ }^{52}$ This is supported by a study which showed that women's pre-pregnancy BMI strongly influenced women's MAP throughout pregnancy in normotensive and chronic hypertensive women alike. ${ }^{28}$

A history of hypertensive pregnancy is known to be associated with higher incidence of high blood pressure, ischaemic heart disease and stroke later in life and occurrence at a younger age. ${ }^{10}{ }^{53-55}$ It was argued that the positive association between gestational hypertension and cardiovascular diseases in later life was caused by their common pathology ${ }^{56}$ Obesity and chronic medical conditions such as diabetes or hypertension, which are among the most recognised risk factors of preeclampsia, ${ }^{9}$ also predispose women to later cardiovascular diseases. This could imply that the associations are due largely to pre-pregnancy risk factors, rather than to factors that operate exclusively in pregnancy. ${ }^{57}$ Pregnancy could be seen as a metabolic and vascular 'stress test' that could unmask women's pre-existing subclinical risks, which may manifest in later life as the effects of ageing and long-term exposure to other classical risk factors emerge ${ }^{53}{ }^{56}$ In addition, excessive gestational weight gain is also associated with long-term maternal abdominal adiposity, which in turn may increase women's risks of cardiovascular and metabolic disease in later life. ${ }^{58}$

Our study showed that women's SBP and DBP increased with higher pre-pregnancy BMI, suggesting a stable linear relation of adiposity and blood pressures during 
pregnancy. This resembles the situations occurring outside of pregnancy, as shown by studies in adults ${ }^{59} 60$ and in children and adolescents ${ }^{61}$ in which adiposity parameters such as BMI were found to be linearly related to the increase in SBP and DBP. We speculate that the difference in blood pressure levels were actually present between women with different BMI before the pregnancy started, persisted during pregnancy and continuously so in the postpartum period. However, we are unable to confirm this hypothesis fully since we do not have data on women's blood pressure prior to pregnancy and postpartum. In contrast, a small study in Brazil showed that although women with excessive weight had higher SBP and DBP than the normal weight women throughout pregnancy, their blood pressures in the postpartum period were comparable. ${ }^{14}$ We do acknowledge that pre-pregnancy BMI is a proxy for body adiposity that may not accurately reflect the distinction between lean body mass and body fat. ${ }^{62}$ What the specific contributions of pre-pregnancy lean body mass and body fat to blood pressure in pregnancy are, remain of interest for future research.

In conclusion, pre-pregnancy BMI, as a proxy measure of adiposity, determined women's blood pressure level during pregnancy but not the pace of its increase. Higher pre-pregnancy BMI was also associated with higher risk for developing gestational hypertension and pre-eclampsia. Gestational weight gain does not appear to mediate these effects. Obese and overweight women in reproductive age should be encouraged to practise a healthy lifestyle which includes weight reduction prior to pregnancy. This intervention could protect them against various pregnancy complications and improve their long-term cardiovascular risks. Women who enter pregnancy with high BMI should be monitored more closely for development of hypertensive disorders during pregnancy.

Twitter Follow Joyce Browne at @JoyceBrowne

Acknowledgements The authors gratefully acknowledge Ika Widyaningrum, Eka Irdianty, Nurulia Rachmat and Erna Rahmawati for their dedication in organising data collection. They would also like to thank all midwives in Budi Kemuliaan Hospital and Budi Kemuliaan Petojo for their contribution to this study. Finally, they would like to thank all the women who have participated in this study.

Contributors AIS and CSPMU contributed to the study concept and design; AIS acquired the data; AIS, PZ and CSPMU analysed, interpreted the data and drafted the manuscript; JLB, DA, MB and DEG critically reviewed the manuscript for important intellectual content; AIS and PZ performed the statistical analysis. All authors read and approved the final manuscript.

Competing interests None declared.

Funding This research received no specific grant from any funding agency in the public, commercial or not-for-profit sectors.

Ethics approval Institutional Review Board of Budi Kemuliaan Hospital.

Provenance and peer review Not commissioned; externally peer reviewed.

Data sharing statement No additional data are available.

Open Access This is an Open Access article distributed in accordance with the Creative Commons Attribution Non Commercial (CC BY-NC 4.0) license, which permits others to distribute, remix, adapt, build upon this work non- commercially, and license their derivative works on different terms, provided the original work is properly cited and the use is non-commercial. See: http:// creativecommons.org/licenses/by-nc/4.0/

\section{REFERENCES}

1. $\mathrm{Ng} \mathrm{M}$, Fleming $\mathrm{T}$, Robinson $\mathrm{M}$, et al. Global, regional, and national prevalence of overweight and obesity in children and adults during 1980-2013: a systematic analysis for the Global Burden of Disease Study 2013. Lancet 2014;384:766-81.

2. Forouzanfar MH, Alexander L, Anderson HR, et al. GBD 2013 Risk Factors Collaborators. Global, regional, and national comparative risk assessment of 79 behavioural, environmental and occupational, and metabolic risks or clusters of risks in 188 countries, 1990-2013: a systematic analysis for the Global Burden of Disease Study 2013. Lancet (London England) 2015;6736:1990-2013.

3. Baeten JM, Bukusi EA, Lambe M. Pregnancy complications and outcomes among overweight and obese nulliparous women. Am J Public Health 2001;91:436-40.

4. Poston L, Harthoorn LF, Van Der Beek EM. Obesity in pregnancy: Implications for the mother and lifelong health of the child. A consensus statement. Pediatr Res 2011;69:175-80.

5. Gaillard R, Steegers EAP, Hofman A, et al. Associations of maternal obesity with blood pressure and the risk of gestational hypertensive disorders. The Generation R Study. J Hypertens 2011;29:937-44.

6. Leung TY, Leung TN, Sahota DS, et al. Trends in maternal obesity and associated risks of adverse pregnancy outcomes in a population of Chinese women. BJOG 2008;115:1529-37.

7. Nucci LB, Schmidt MI, Duncan BB, et al. Nutritional status of pregnant women: prevalence and associated pregnancy outcomes. Rev Saude Publica 2001;35:502-7. [pii]

8. Kumari AS. Pregnancy outcome in women with morbid obesity. Int J Gynaecol Obstet 2001;73:101-7.

9. Duckitt K, Harrington D. Risk factors for pre-eclampsia at antenatal booking: systematic review of controlled studies. BMJ 2005;330:565.

10. Samuels-Kalow ME, Funai EF, Buhimschi C, et al. Prepregnancy body mass index, hypertensive disorders of pregnancy, and long-term maternal mortality. Am J Obstet Gynecol 2007;197:1-6.

11. Leslie MS, Briggs LA. Preeclampsia and the risk of future vascular disease and mortality: a review. J Midwifery Womens Health 2016;61:315-24.

12. Bhattacharya S, Campbell DM, Liston WA, et al. Effect of body mass index on pregnancy outcomes in nulliparous women delivering singleton babies. BMC Public Health 2007;7:168.

13. Leeners B, Rath W, Kuse S, et al. BMI: new aspects of a classical risk factor for hypertensive disorders in pregnancy. Clin Sci 2006:111:81-6.

14. Rebelo F, Farias DR, Mendes RH, et al. Blood pressure variation throughout pregnancy according to early gestational BMI: a Brazilian cohort. Arq Bras Cardiol 2015;104:284-91.

15. Miller RS, Thompson ML, Williams MA. Trimester-specific blood pressure levels in relation to maternal pre-pregnancy body mass index. Paediatr Perinat Epidemiol 2007;21:487-94. http://ovidsp.ovid.com/ovidweb.cgi? $\mathrm{T}=\mathrm{JS} \& \mathrm{PAGE}=$ reference\&D=emed8\&NEWS=N\&AN=2007512062. .

16. Thompson ML, Williams MA, Miller RS. Modelling the association of blood pressure during pregnancy with gestational age and body mass index. Paediatr Perinat Epidemiol 2009;23:254-63.

17. Li C, Liu Y, Zhang W. Joint and independent associations of gestational weight gain and pre-pregnancy body mass index with outcomes of pregnancy in Chinese women: a retrospective cohort study. PLOS ONE 2015;10:e0136850.

18. Saftlas AF, Wang W, Risch $\mathrm{H}$, et al. Prepregnancy body mass index and gestational weight gain as risk factors for preeclampsia and transient hypertension. Ann Epidemiol 2000;10:475.

19. Strevens H, Wide-Swensson D, Ingemarsson I. Blood pressure during pregnancy in a Swedish population; impact of parity. Acta Obstet Gynecol Scand 2001;80:824-9. http://www.ncbi.nlm.nih.gov/ pubmed/11531633.

20. Wells CS, Schwalberg R, Noonan G, et al. Factors influencing inadequate and excessive weight gain in pregnancy: Colorado, 2000-2002. Matern Child Health J 2006;10:55-62.

21. Tranquilli AL, Dekker G, Magee L, et al. The classification, diagnosis and management of the hypertensive disorders of pregnancy: a revised statement from the ISSHP. Pregnancy Hypertens 2014;4:97-104.

22. Han TS, Hart CL, Haig C, et al. Contributions of maternal and paternal adiposity and smoking to adult offspring adiposity and cardiovascular risk: the Midspan Family Study. BMJ Open 2015;5: e007682. 
23. Colell E, Sánchez-Niubò A, Domingo-Salvany A. Sex differences in the cumulative incidence of substance use by birth cohort. Int $J$ Drug Policy 2013;24:319-25.

24. Barraclough S. Women and tobacco in Indonesia. Tob Control 1999;8:327-32.

25. Palipudi K, Mbulo L, Kosen S, et alA cross sectional study of Kretek smoking in Indonesia as a major risk to public health. Asian Pac $J$ Cancer Prev 2015;16:6883-8.

26. Macdonald-Wallis C, Silverwood RJ, Fraser A, et al. Gestational-age-specific reference ranges for blood pressure in pregnancy. J Hypertens 2015;33:96-105.

27. WHO Expert Consultation. Appropriate body-mass index for Asian populations and its implications for policy and intervention strategies. Lancet 2004;363:157-63.

28. Guedes-Martins L, Carvalho M, Silva $C$, et al. Relationship between body mass index and mean arterial pressure in normotensive and chronic hypertensive pregnant women: a prospective, longitudinal study. BMC Pregnancy Childbirth 2015;15:281.

29. American College of Obstetricians and Gynecologists' Task Force on Hypertension in Pregnancy. Hypertension in pregnancy. Obstet Gynecol 2013:122:1122-31.

30. Chen Z, Du J, Shao L, et al. Prepregnancy body mass index, gestational weight gain, and pregnancy outcomes in China. Int J Gynaecol Obstet 2010;109:41-4.

31. Fortner RT, Pekow P, Solomon CG, et al. Prepregnancy body mass index, gestational weight gain, and risk of hypertensive pregnancy among Latina women. Am J Obstet Gynecol 2009;200:167.e1-169.

32. Mbah AK, Kornosky JL, Kristensen $\mathrm{S}$, et al. Super-obesity and risk for early and late pre-eclampsia. BJOG 2010;117:997-1003.

33. Liu L, Hong Z, Zhang L. Associations of prepregnancy body mass index and gestational weight gain with pregnancy outcomes in nulliparous women delivering single live babies. Sci Rep 2015;5:12863.

34. Valsamakis G, Kyriazi EL, Mouslech Z, et al. Effect of maternal obesity on pregnancy outcomes and long-term metabolic consequences. Hormones (Athens) 2015;14:345-57.

35. Weiss JL, Malone FD, Emig D, et al. Obesity, obstetric complications and cesarean delivery rate-a population-based screening study. Am J Obstet Gynecol 2004;190:1091-7.

36. Bodnar LM, Ness RB, Markovic N, et al. The risk of preeclampsia rises with increasing prepregnancy body mass index. Ann Epidemio 2005;15:475-82.

37. Papachatzi E, Dimitriou G, Dimitropoulos K, et al. Pre-pregnancy obesity: maternal, neonatal and childhood outcomes. J Neonatal Perinatal Med 2013;6:203-16.

38. Athukorala C, Rumbold AR, Willson KJ, et al. The risk of adverse pregnancy outcomes in women who are overweight or obese. BMC Pregnancy Childbirth 2010;10:56.

39. Doherty DA, Magann EF, Francis J, et al. Pre-pregnancy body mass index and pregnancy outcomes. Int $J$ Gynaecol Obstet 2006;95:242-7.

40. Abenhaim HA, Kinch RA, Morin L, et al. Effect of prepregnancy body mass index categories on obstetrical and neonatal outcomes. Arch Gynecol Obstet 2007;275:39-43.

41. Flick AA, Brookfield KF, de la Torre L, et al. Excessive weight gain among obese women and pregnancy outcomes. Am J Perinatol 2010;27:333-8.

42. Van Der Linden EL, Browne JL, Vissers KM, et al. Maternal body mass index and adverse pregnancy outcomes: a Ghanaian cohort study. Trop Med Int Health 2015;20:72-3.
43. Thomson A, Billewicz W. Clinical significance of weight trends during pregnancy. BMJ 1957;1:243-7.

44. Michael A, Mary Z, Christine O, et al. Increased leptin levels in preeclampsia: associations with BMI, estrogen and SHBG levels. Hormones (Athens) 2004;3:46-52.

45. Taylor BD, Ness RB, Olsen J, et al. Serum leptin measured in early pregnancy is higher in women with preeclampsia compared with normotensive pregnant women. Hypertension 2015;65:594-9.

46. Wolf M, Sandler L, Muñoz K, et al. First trimester insulin resistance and subsequent preeclampsia: a prospective study. J Clin Endocrinol Metab 2002;87:1563-8.

47. Helmreich RJ, Hundley V, Varvel P. The effect of obesity on heart rate (heart period) and physiologic parameters during pregnancy. Biol Res Nurs 2008;10:63-78.

48. Esler M, Straznicky N, Eikelis N, et al. Mechanisms of sympathetic activation in obesity-related hypertension. Hypertension 2006;48:787-96.

49. Grassi G. Role of the sympathetic nervous system in human hypertension. J Hypertens 1998;16:1979-87.

50. Calhoun DA, Grassi G. Weight gain and hypertension: the chicken-egg question revisited. $J$ Hypertens 2004;22:1869-71. http://www.ncbi.nlm.nih.gov/pubmed/15361756.

51. Julius S, Valentini M, Palatini P. Overweight and hypertension. A 2-way street? Hypertension 2000;35:807-13.

52. Redman CWG, Sargent IL. Pre-eclampsia, the placenta and the maternal systemic inflammatory response-a review. Placenta 2003;24(Suppl A):21-7.

53. Sattar N, Greer IA. Pregnancy complications and maternal cardiovascular risk: opportunities for intervention and screening? BMJ 2002;325:157-60.

54. Sattar N. Do pregnancy complications and CVD share common antecedents? Atheroscler Suppl 2004;5:3-7.

55. Tooher J, Chiu CL, Yeung K, et al. High blood pressure during pregnancy is associated with future cardiovascular disease: an observational cohort study. BMJ Open 2013;3:1-8.

56. Williams D. Pregnancy: a stress test for life. Curr Opin Obstet Gynecol 2003;15:465-71.

57. Romundstad PR, Magnussen EB, Smith GD, et al. Hypertension in pregnancy and later cardiovascular risk: common antecedents? Circulation 2010;122:579-84

58. McClure CK, Catov JM, Ness R, et al. Associations between gestational weight gain and BMI, abdominal adiposity, and traditional measures of cardiometabolic risk in mothers 8 y postpartum. Am J Clin Nutr 2013:98:1218-25.

59. Doll S, Paccaud F, Bovet $\mathrm{P}$, et al. Body mass index, abdominal adiposity and blood pressure: consistency of their association across developing and developed countries. Int J Obes Relat Metab Disord 2002;26:48-57.

60. Yang G, Xiang YB, Zheng W, et al. Body weight and weight change in relation to blood pressure in normotensive men. $J$ Hum Hypertens 2007;21:45-52.

61. Paradis G, Lambert M, O'Loughlin J. Blood pressure and adiposity in children and adolescents. Circulation 2004; 110:1832-8.

62. Romero-Corral A, Somers VK, Sierra-Johnson J, et al. Accuracy of body mass index in diagnosing obesity in the adult general population. Int J Obes (Lond) 2008;32:959-66. 